\title{
ALK NP_004295.2:p.I1170S
}

National Cancer Institute

\section{Source}

National Cancer Institute. ALK NP 004295.2:p.I1170S. NCI Thesaurus. Code C133480.

A change in the amino acid residue at position 1170 in the ALK tyrosine kinase receptor protein where isoleucine has been replaced by serine. 